Womens Health Issues. 2012 September ; 22(5): e421-e428. doi:10.1016/j.whi.2012.06.002.

\title{
Factors facilitating acceptable mammography services for women with disabilities
}

\author{
Molly P. Jarman, MPH \\ University of North Carolina at Chapel Hill Department of Radiology UNC-CH CB\# 7515 Chapel \\ Hill, NC 27599
}

\author{
J. Michael Bowling, PhD \\ University of North Carolina at Chapel Hill Department of Health Behavior and Health Education \\ UNC-CH CB\# 7440 Chapel Hill, NC 27599 Phone: (919) 302-8166 Fax: (919) 928-8955 \\ jbowling@email.unc.edu
}

\section{Pamela Dickens, MPH}

University of North Carolina at Chapel Hill FPG Child Development Institute UNC-CH CB\# 8185 Chapel Hill, NC 27599 Phone: (919) 966-0871 Fax: (919) 966-0862 pam.dickens@unc.edu

\section{Karen Luken, MSRA}

University of North Carolina at Chapel Hill FPG Child Development Institute UNC-CH CB\# 8185 Chapel Hill, NC 27599 Phone: (919) 966-0881 Fax: (919) 962-5777 karen.luken@unc.edu

\section{Bonnie C. Yankaskas, PhD}

University of North Carolina at Chapel Hill Department of Radiology UNC-CH CB\# 7515 Phone: (919) 966-0462 Fax: (919) 966-0525 bcy@unc.edu

\section{Abstract}

Introduction and Background-Prior research has described general barriers to breast cancer screening for women with disabilities (WWD). We explored specific accommodations described as necessary by WWD who have accessed screening services, and the presence of such accommodations in community based screening programs.

Methods-We surveyed WWD in the Carolina Mammography Registry to determine what accommodations were needed when accessing breast screening services, and whether or not these needs were met. The sample of 1,348 WWD was identified through a survey of limitations, with a

(C) 2012 Jacobs Institute of Women's Health. Published by Elsevier Inc. All rights reserved

Molly P. Jarman, MPH (Cooresponding author) Phone: (919) 966-2865 Fax: (919) 966-0525 mpjarman@ med.unc.edu. Molly P. Jarman, MPH, is a research specialist in the UNC-CH Department of Radiology. Her research focuses on use and performance of breast cancer screening services.

J. Michael Bowling, PhD, is a Research Associate Professor of Health Behavior and Health Education, and an Adjunct Research Associate Professor of Biostatistics, UNC-CH. He has significant experience in questionnaire development and survey administration. Pamela Dickens, MPH, is the Women's Health Coordinator for the North Carolina Office on Disability and Health. Her research interests include health care access and utilization, and health disparities for women with disabilities.

Karen Luken, MSRA, is an investigator with the North Carolina Office on Disability and Health. Her research interests include accessibility and utilization of health care services for people with disabilities.

Bonnie C. Yankaskas, PhD, is a Professor Emeritus in the Department of Radiology, UNC-CH, who created the Carolina Mammography Registry, and has published widely on breast cancer screening. Her areas of interest include screening performance, dissemination of emerging technologies, and disparities in cancer treatment and outcomes.

Publisher's Disclaimer: This is a PDF file of an unedited manuscript that has been accepted for publication. As a service to our customers we are providing this early version of the manuscript. The manuscript will undergo copyediting, typesetting, and review of the resulting proof before it is published in its final citable form. Please note that during the production process errors may be discovered which could affect the content, and all legal disclaimers that apply to the journal pertain. 
response rate of $45.5 \%(4,498 / 9,885)$. Of the 1,348 WWD eligible for the second survey, 739 responded for a response rate of $54.8 \%$.

Results-The most frequently needed accommodations were an accessible changing area with a bench $(60.0 \%)$, oral description of the procedure by the technologist $(60.5 \%)$, and handicapped/ accessible parking (27.6\%). Handicapped parking was the need most likely to go unmet (3.1\%).

Conclusions-Most needs are being met by radiology facilities and staff, and the few needs going unmet are related to the physical/built environment. Overall, for WWD who are in screening, the mammography system appears to be more accessible than generally perceived.

\section{Background}

People with disabilities constitute a sizable and understudied group in the US. According to the US Census 2000, 22.2\% of adult women have some type of disability (US Census Bureau, 2011). The 2009 North Carolina Behavioral Risk Factor Surveillance System (NC BRFSS) documented that $32.1 \%$ of non-institutionalized female adults in NC, age 18 and older as having a disability (approximately 1.4 million) (North Carolina State Center for Health Statistics, 2011). A person is considered to have a disability if she needs assistance to perform an activity, uses adaptive equipment, or requires standby help. The limitation is expected to be permanent or chronic in duration (North Carolina Office of Disability and Health, 2004). Disability and daily activity are multidimensional and complex concepts.

Disparities in use of health screenings by persons with disabilities are documented in Healthy People 2010 (Department of Health and Human Services [DHHS], 2011). In particular, women with disabilities (WWD) often get mammography screening at a lower rate than women without disabilities (WWOD), resulting in screening disparities and breast cancers diagnosed at a more advanced stage (Roetzheim \& Chirikos, 2002). Furthermore, women at the highest risk of breast cancer, African Americans and older women of all races (American Cancer Society [ACS], 2010), also have a higher prevalence of disability than other groups of women. (Centers for Disease Control and Prevention [CDC], 2010). Disparities in screening for women with disabilities are particularly worrying as breast cancer is the second most common cancer among women in the United States after skin cancer; and is the second leading cause of cancer deaths among women (American Cancer Society [ACS], 2010). At this time, mammography is the best screening method for breast cancer and routine screening mammography can reduce breast cancer deaths by as much as $20 \%$ (National Cancer Institute [NCI], 2010). Regular screening mammograms are recommended for all women, regardless of disability, beginning as early as 40 years of age (USPSTF, 2009; American College of Radiology, 2008; Susan G. Komen for the Cure, 2008; ACS, 2008).

Iezzoni et al. examined the use of screening and preventive services among women with mobility disabilities and found that women who had major lower extremity mobility limitations were less likely to receive a mammogram (Iezzoni, McCarthy, Davis, HarrisDavid, \& O'Day, 2001). The United States Department of Health and Human Services Office on Disability found that only 54\% of WWD over 40 years of age have had a mammogram, compared to 68\% of WWOD (DHHS, 2005). Furthermore, Roetzheim et al found that cancer diagnoses for WWD were made at a more advanced stage than for WWOD (Roetzheim \& Chirikos, 2002).

There is also growing evidence that people with disabilities experience more problems with the safety and quality of their health care than do those without disabilities (Iezzoni, 2006). Prior studies consistently report barriers such as physical limitations in the built environment, physically inaccessible healthcare facilities or medical equipment, 
communication difficulties, staff attitudes, lack of disability knowledge among healthcare professionals, lack of transportation, and lack of clinical recommendation (Iezzoni, Davis, Soukup, \& O'Day, 2002; Kroll, Jones, Kehn, \& Neri, 2006; McCarthy, Ngo, Roetzheim, \& Chirikos, 2006; Morrison, George, \& Mosqueda, 2008; Roetzheim \& Chirikos, 2002; Smeltzer, Sharts-Hopko, Ott, Zimmerman, \& Duffin, 2007). Prior work by the investigators of this study indicated that WWD face more barriers to screening and are less satisfied with their overall screening experience than WWOD (Yankaskas et al., 2009). The barriers have been studied but no one has asked WWD themselves what they need when getting their mammograms and whether these needs are being met. Knowing what is working for women who are getting screened as well as what needs are not being met is valuable information for health care professionals and facilities that are committed to ensuring all women get screened. This study asked WWD who were being screened what their needs were and whether or not their needs were being met.

\section{Methods}

\section{Study Setting}

Women receiving screening mammograms at facilities participating in the Carolina Mammography Registry (CMR) were eligible for inclusion in this study. CMR is a population-based mammography registry that links community-based mammography data with NC Central Cancer Registry data for study of screening patterns and outcomes. CMR collects prospective data from mammography facilities in 34 counties across North Carolina (CMR, 2011). Data are collected from women on all breast imaging at each visit in the facilities and include: demographics (date of birth, race, educational level), personal history of breast cancer, family history of breast cancer, history of breast procedures, menopausal status, hormone use, height and weight, and date of last mammogram. The technologists and radiologists record information about imaging procedures, breast density, the radiologist's impressions and recommendations for follow-up. CMR collects benign and malignant pathology reports on an ongoing basis, and links annually with the North Carolina Central Cancer Registry to collect cancer outcome data. CMR is annually approved by the University of North Carolina at Chapel Hill Biomedical Institutional Review Board, holds a US Public Health Service Certificate of Confidentiality and is HIPAA compliant.

\section{Study Sample}

All 34 active CMR practices active in 2006 were invited to participate in the study. Practices were asked to send a letter provided by the study authors to their patients who had not returned for screening for three years following their last mammogram, as identified by CMR. The three year time frame was established to account for women following a biannual screening schedule based on physician recommendation and/or screening guidelines. Mammograms performed within 9-18 months of the prior screening mammogram are classified as annual screens. Mammograms more than 18 months but less than 30 months after the prior screening mammogram are classified as bi-annual screens. Women were selected for the study if they were age 40 or older, their last mammogram was negative, and they had not returned to screening since December 31, 2003. We did not include women younger than 40 as there is no recommendation for screening in these younger women. There are no recommendations for women 74 and older, however the Registry has large numbers of older women who are screened and the cancer rates do not decline, thus we did not set an upper age limit for the study population.

Ten of the practices agreed to participate. We excluded one small practice with a small number of eligible women. We identified 10,036 women who met the inclusion criteria. Of these women, 151 (1.5\%) either had incomplete addresses or were deceased, leaving 9,885 
who received the initial questionnaire via mail. The practices included in the study serve a combination of urban and rural regions, with two serving predominantly urban communities, four serving predominantly rural communities, and four serving mixed urban/rural communities. The initial questionnaire was designed to identify WWD with physical or sensory disabilities using relevant questions from pre-existing questionnaires designed to collect data about barriers to mammography and disability information, with expert help from Bowling (O'Neill et al., 2008) and Skinner (Skinner, 1997), two experienced survey methodologists. Of the 9,885 in the original sample, 4,498 (45.5\%) responded to the first questionnaire, and 1,055 (35.5\%) were identified as having a disability. We mailed a second questionnaire to 1,348 women (13\% of the original sample) who agreed to participate in further research and who were identified as WWD based on the first questionnaire, including 1,396 (14.1\%) women who reported having a mammogram in the three years prior to the study.

\section{Questionnaire}

The questionnaire was designed to identify what accommodations WWD need at the time of their mammography appointments. The questionnaire included 38 items to assess if each accommodation was needed, and if the need was met or not. Time to complete the questionnaire was estimated to be 15 minutes. Questions were developed based on a review of the literature to identify possible barriers throughout the mammography process from the initial scheduling contact with the practice through the completion of the mammogram. Women with and without disabilities not in the study sample reviewed the questions for clarity throughout the development process. The questionnaire was pilot tested with a small subset of the sample and adjusted as needed before distribution to the sample at large. Details about the questionnaire development were previously published (Yankaskas, et al., 2009).

\section{Recruitment}

Survey methodology was guided by best practices published by Dillman (Dillman \& CarleyBaxter, 2001; Dillman, 2000; Dillman, et al., 1995). A letter accompanied the questionnaire to the study group thanking each woman for completing the initial survey and agreeing to participate in further research. The letter stated that responses on the initial questionnaire indicated that the woman may have limitations in her daily activities and that data collected with the second questionnaire would be used by the practice to help improve service to their patients, and combined with data from other practices, would be used for research by CMR. Each questionnaire packet included a stamped envelope addressed to the Center for Women's Health Research at UNC-CH and a two-dollar bill as an incentive. Reminder postcards were mailed at week two, followed by a second copy of the questionnaire (without cash incentive) at week four. As questionnaires were returned, each was logged in and the information entered into the data base for later analysis. All data were double entered and checked for data errors.

\section{Analysis}

Data collected through the survey were linked with information reported by subjects at their most recent breast imaging appointment within CMR. We compared responders to nonresponders from the sample of subjects eligible for the second survey, with respect to age, race, and educational level using one-sample $\mathrm{x}^{2}$ tests. Education is an optional variable, and is not available from all study sites. WWD were divided into four groups based on selfreported limitations in the first questionnaire: physical limitation, hearing limitation, visual limitation, and multiple limitations (any combination of physical, hearing, and/or visual). 
We computed descriptive statistics of accommodations needed for all responders as a whole and for each distinct disability group, and stratified by subjects' age and race. We used two age groups, 40 to 64 years and 65 and older, based on the age of Medicare eligibility and the strong relationship between age and disability. The CMR population reflects the racial/ ethnic distribution of North Carolina, with large White and Black/African American populations. Other racial/ethnic groups do not comprise a large enough segment of the study sample for separate analysis, and therefore are combined into a single "Other" group.

\section{Results Response}

Of the 1,348 subjects in the sample, 739 returned completed questionnaires (54.8\%). Women age 50 to 69 responded at a slightly higher rate than women younger than 50 or older than $70(p=0.04)$. There was no significant difference in the race/ethnic or education distribution of responders compared to non-responders (Table 1). The distribution of disability types (59.4\% physical, $8.7 \%$ hearing, $6.6 \%$ visual, and $25.3 \%$ multiple disabilities) was comparable to the distribution found in the first survey (Yankaskas et al., 2009).

\section{Needs and Accommodations}

We asked women if they needed any of 28 accommodations during their last mammography appointment, and if their need was met. Most accommodations were needed by fewer than $25 \%$ of respondents (Table 2). Five were noted as "needed" by more than $25 \%$ : accessible changing area $(63.0 \%)$, oral description of the procedure by the technologist $(60.4 \%)$, changing bench in the dressing room (57.0\%), handicapped parking (30.5\%), and staff assistance during the appointment $(25.6 \%)$. Of the women reporting they needed specific accommodations, very few reported that their needs were not met. The three needs most likely to go unmet were handicapped parking (3.1\%), being able to sit during the mammogram (2.5\%), and handrails next to changing bench (2.2\%). While there were differences in accommodations needed and not needed by disability type, race, and age, there were no significant differences in unmet needs. For this reason, "needed, need met" and "needed, need not met" are combined in a single "needed" category.

\section{Needs by disability type}

Women with multiple disabilities were more likely to need staff assistance during the appointment than women with only hearing, vision or physical disabilities ( $38.1 \%$ vs. $25.3 \%, 16.7 \%$ and $21.6 \%, p<0.001)$ and use of alternate communication by staff member in the waiting room $(12.0 \%$ vs. $0.0 \%, 6.2 \%$ and $5.4 \%, p=0.018)$. Women with multiple and with only physical disabilities were more likely to need a handicapped parking spaces than women with only hearing or only vision disabilities $(42.6 \%$ and $32.3 \%$ vs. $9.9 \%$ and $0.0 \%, p$ $<0.001$ ), as well as handrails by the building entrance (33.8\% and $21.7 \%$ vs. $12.1 \%$ and $3.4 \%, p<0.001)$, a ramped or level entrance $(36.7 \%$ and $25.5 \%$ vs. $7.9 \%$ and $1.7 \%, p<$ 0.001 ), wide doorways ( $30.5 \%$ and $14.0 \%$ vs. $4.6 \%$ and $0.0 \%, p<0.001$ ), an elevator (28.3\% and $19.1 \%$ vs. $6.6 \%$ and $9.3 \%, p<0.001)$, a low reception station $(21.3 \%$ and 13.6 $\%$ vs. $6.6 \%$ and $1.8 \%, p<0.001)$, changing benches $(63.6 \%$ and $59.4 \%$ vs. $41.6 \%$ and $33.6 \%, p<0.001)$, handrails next to changing bench $(22.5 \%$ and $14.0 \%$ vs. $8.8 \%$ and $3.4 \%$, $p<0.001)$, room to turn a wheelchair in the changing area $(12.2 \%$ and $6.9 \%$ vs. $0.0 \%$ and $0.0 \%, p<0.001)$, an accessible private dressing area $(66.3 \%$ and $66.0 \%$ vs. $52.7 \%$ and $42.4 \%, p<0.001$ ), wide pathways for wheelchairs ( $14.7 \%$ and $6.2 \%$ vs. $0.0 \%$ and $0.0 \%, p<$ $0.001)$, room to turn a wheelchair next to machine $(14.1 \%$ and $6.2 \%$ vs. $0.0 \%$ and $0.0 \%, p<$ 0.001 ), sitting during mammogram ( $16.8 \%$ and $12.1 \%$ vs. $2.2 \%$ and $1.7 \%, p<0.001)$, an accessible toilet $(18.2 \%$ and $14.5 \%$ vs. $0.0 \%$ and $1.7 \%, p<0.001)$, and staff use of Relay NC (7.4\% and $5.3 \%$ vs. $0.0 \%$ and $0.0 \%, p=0.046)$. Women with multiple disabilities and 
with hearing only disabilities were more likely to need staff assistance with paper work than women with vision or physical only disabilities $(13.4 \%$ and $15.4 \%$ vs. $6.7 \%$ and $9.8 \%, p<$ $0.001)$, as well as alternate formats for printed materials (16.3\% and $11.5 \%$ vs. $5.3 \%$ and $8.3 \%, p+0.036$ ). Women with multiple disabilities, only physical disabilities, and only vision disabilities were more likely to need accessible restroom fixtures than women with only hearing disabilities $(27.2 \%, 24.6 \%$, and $16.9 \%$ vs. $3.3 \%, p<0.001)$. (Table 3 ).

\section{Needs by age, race/ethnicity}

Women age 65 and older were more likely to need handicapped parking than women younger than $65(40.2 \%$ vs. $24.9 \%, p<0.001)$, as well as handrails by the building entrance (29.7\% vs. $18.1 \%, p<0.001)$, a level/ramped building entrance (30.6\% vs. $21.7 \%, p=$ $0.008)$, an accessible dressing area (68.6\% vs. $59.9 \%, p=.018)$, and an accessible toilet $(17.6 \%$ vs. $10.6 \%, p=0.008)$. Women younger than 65 were more likely to need a service animal during their mammography appointment than their older counterparts (5.8\% vs. $2.0 \%, p=.023)$. (Table 4).

Black/African American women (38.2\%) and other race/ethnicity women (31.8\%) were more likely to need staff assistance during the appointment than White women $(24.1 \%, p=$ $0.010)$, as well as staff assistance with paperwork (Black $=29.7 \%$, Other $=22.7 \%$, White $=$ $17.5 \%, p=0.016)$. Black/African American women were more likely to need extra time during the appointment than both Other race/ethnicity and White women $(19.0 \%, 9.1 \%$, and $9.9 \%$ respectively, $p=0.029)$. Other race/ethnicity women $(90.9 \%)$ were more likely to need an oral description of the procedure as it was happening than Black or White women $(68.5 \%, 57.8 \%, p=0.041)$. (Table 5).

\section{Discussion}

We identified WWD and WWOD in a large community-based mammography population and asked participants what accommodations they needed during their mammogram appointments, and if those needs were met. While other studies have presented quantitative evidence of disparities in breast cancer outcomes and qualitative evidence of barriers to mammography services for WWD (Iezzoni et al, 2001; Kroll et al, 2006; McCarthy et al, 2006; Morrison et al, 2008; North Carolina Office of Disability and Health, 2004; Roetzheim \& Chirikos, 2002; Smeltzer et al, 2007), there has been no research to date evaluating what accommodations women require when having a mammogram, and the availability of those accommodations. A 2001 analysis of National Health Interview Survey data found disparities in breast cancer screening participation among a national sample of WWD, but did not explore reasons for failure to screen (Iezzoni et al, 2001). A 2002 analysis of SEER-Medicare data found parallel disparities in breast cancer stage at diagnosis and outcomes, but again did not explore causes for such disparities (Roetzheim \& Chirikos, 2002). Further exploration of SEER-Medicare data in 2006 reinforced the evidence of poorer breast cancer outcomes for WWD (McCarthy et al, 2006). All three analyses studies used secondary data from nationally representative samples. A 2003 report on disability in North Carolina found significant disparities in use of breast cancer screening services by WWD. Data for the report came from the NC BRFSS and were both representative of the state and comparable to the demographic distribution of the population included in our study (North Carolina Office of Disability and Health, 2004). Several qualitative studies have used focus groups to explore general barriers to medical care for people with disabilities, though none specifically addressed breast cancer screening, and only one targeted WWD (Kroll et al, 2006; Morrison et al, 2008; Smeltzer et al, 2007).

Overall, our findings portray a more accessible mammography system than indicated in previous studies. The WWD in our sample identified a small number of needed 
accommodations and reported that radiology facilities and staff met most needs, indicating that radiology facilities in the community are largely accessible. The few needs going unmet by more than $1 \%$ of subjects are almost exclusively related to the physical layout of the facility, which suggests a need to focus on the ADA Standards for Accessible Design and principles of Universal Design (US Department of Justice, 2010) as new facilities are built, existing facilities undergo renovation, and simple solutions are found that do not require major renovations. It is possible that some needs go unmet despite available accommodations because patients are not aware of their availability and/or do not request them. Efforts to educate both medical professionals and WWD may increase overall accessibility in such cases.

In general, women with multiple disabilities need more accommodations that other WWD. Women with multiple disabilities or physical disabilities were more likely to need structural accommodations than women with hearing or vision disabilities. This is not surprising given the limitations inherent to physical disabilities. Older women and minorities were more likely to need some accommodations than younger women and White women. Many of these needs were related to physical disabilities that increase with age. We did not explore the reason for Black and Other women having more needs, but it may be that they have more disability related to chronic disease. Regardless, even with these differences, this study indicates that there is little evidence that needs are going unmet, and on the whole the unmet needs are things that can be improved through staff training and low cost solutions.

\section{Study Limitations}

The sample size for the questionnaire was limited by subjects' agreement to contact by the study team, but the proportion of the original sample identified as having a disability is comparable to the statewide prevalence of disability, and the distribution of disability types among women who completed the questionnaire (59.4\% physical, $8.7 \%$ hearing, $6.6 \%$ vision, $25.3 \%$ multiple) was comparable to the distribution of disabilities in the original study sample (64.4\%, 7.9\%, 5.7\%, and 22.1\% respectively) (Yankaskas, et al. 2009). In order to accommodate one and two year screening regimens, the sample was limited to women who had not returned to screening in at least three years, and responses may be limited by participants ability to recall their last mammogram appointment. The study sample was also limited to women who have used breast cancer screening services at least once, and we acknowledge that we do not know what women who have never been screened would identify as their needs.

This study used data from a limited population in a single state, and may not be generalizable to women with disabilities in other communities. Participants in the study are representative of the population of North Carolina in terms of age and race, as well as urban/ rural distribution. While the study population is not directly representative of the national population, there is no reason to believe the needs and experiences of WWD in our population are different from WWD in other communities. In light of limitations on the generalizability of this study, we hope others may be able to apply our methods in their communities to assess accessibility of mammography services.

\section{Conclusions}

It is important to go beyond identifying barriers and understand what is working for WWD when we look at screening for WWD and other minority groups. Ideally we want to build a picture of what the needs are, how they are being met, and what needs are unmet and how they can be addressed. The ultimate goal is to have all women get to screening and continue to receive screenings at the recommended intervals. From our previous work (Yankaskas, et al., 2009), we know that reasons given for not returning were predominantly not having a 
recommendation from their physician, and the discomfort, pain and cost associated with the mammogram. WWD were more likely not to receive a recommendation for screening by their physicians compared to WWOD. In addition, we have learned that once women get to screening, adherence to screening recommendations will be enhanced when accessibility and accommodations are considered part of the standard practices for all mammography screening sites.

\section{Acknowledgments}

The study was supported by grants from Susan G. Komen for the Cure (POP35606) and the National Cancer Institute (CA 7004).

\section{References}

American Cancer Society. American Cancer Society Guidelines for the Early Detection of Cancer. 2008. Retrieved July 9, 2009 from http://www.cancer.org/docroot/PED/content/ PED_2_3X_ACS_Cancer_Detection_Guidelines_36.asp?sitearea=PED

American Cancer Society. Cancer Facts \& Figures 2010. American Cancer Society; Atlanta: 2010. Retrieved October 31, 2011 from http://www.cancer.org/acs/groups/content/@epidemiologysurveilance/documents/document/acsp c-026238.pdf

American College of Radiology. ACR practice guideline for the performance of screening and diagnostic mammography. Practice Guidelines and Technical Standards. 2008. Retrieved January 31, 2011, 2011, from http://www.acr.org/SecondaryMainMenuCategories/quality_safety/guidelines/breast/Screening Diagnostic.aspx

Carolina Mammography Registry. CMR Overview. 2011. Retrieved October 31, 2011 from http://www.unc.edu/cmr/whatWeDo.shtml

Centers for Disease Control and Prevention. Behavioral Risk Factor Surveillance System Prevalence and Trends Data. 2010. Retrieved February 20, 2012 from http://apps.nccd.cdc.gov/brfss/

Dillman, D.; Carley-Baxter, L. Structural determinants of mail survey response rates over a 12-year period, 1989 -1999; Paper presented at the Proceedings of American Statistical Association Survey Methods Section; Alexandria, VA. 2001.

Dillman, DA. Mail and Internet Surveys: The Tailored Design Method. Wiley; New York: 2000.

Dillman DA, Jon R. Clark, Michael A. Sinclair. How Prenotice Letters, Stamped Return Envelopes, and Reminder Postcards Affect Mailback Response Rates for Census Questionnaires. Survey Methodology. 1995; 21:7.

Humphrey LL, Helfand M, Chan BK, Woolf SH. Breast cancer screening: a summary of the evidence for the U.S. Preventive Services Task Force. Ann Intern Med. 2002; 137:347-360. [PubMed: 12204020]

Iezzoni L. Improving health care quality and safety for people with disabilities: an interview with Lisa Iezzoni. Interview by Steven Berman. Jt Comm J Qual Patient Saf. 2006; 32(7):400-406. 357. [PubMed: 16884127]

Iezzoni LI, Davis RB, Soukup J, O'Day B. Satisfaction with quality and access to health care among people with disabling conditions. Int J Qual Health Care. 2002; 14(5):369-381. [PubMed: 12389803]

Iezzoni LI, Freedman VA. Turning the disability tide: the importance of definitions. JAMA. 2008; 299(3):332-334. [PubMed: 18212318]

Iezzoni LI, McCarthy EP, Davis RB, Harris-David L, O'Day B. Use of screening and preventive services among women with disabilities. Am J Med Qual. 2001; 16(4):135-144. [PubMed: 11477958] 
Kroll T, Jones GC, Kehn M, Neri MT. Barriers and strategies affecting the utilization of primary preventive services for people with physical disabilities: a qualitative inquiry. Health Soc Care Community. 2006; 14(4):284-293. [PubMed: 16787479]

McCarthy EP, Ngo LH, Roetzheim RG, Chirikos TN, Li D, Drews RE, et al. Disparities in breast cancer treatment and survival for women with disabilities. Ann Intern Med. 2006; 145(9):637645. [PubMed: 17088576]

Morrison EH, George V, Mosqueda L. Primary care for adults with physical disabilities: perceptions from consumer and provider focus groups. Fam Med. 2008; 40(9):645-651. [PubMed: 18830840]

National Cancer Institute. Screening Mammography: Help With Explaining Benefits and Potential Harms. Oct 1. 2010 Retrieved October 31, 2011, from http://www.cancer.gov/cancertopics/screening/breast/mammography-benefits-harms

North Carolina State Center for Health Statistics. Behavioral Risk Factor Surveillance System (BRFSS) Calendar Year 2009 Results. 2011. Retrieved October 31, 2011 from http://www.epi.state.nc.us/SCHS/brfss/2009/

North Carolina Office of Disability and Health. State Center for Health Statistics. Health and disability in North Carolina, 2003: A joint report from the NC office on disability and health and the state center for health statistics. Raleigh, NC: 2004.

O'Neill SC, Bowling JM, Brewer NT, Lipkus IM, Skinner CS, Strigo TS, et al. Intentions to maintain adherence to mammography. J Womens Health (Larchmt). 2008; 17(7):1133-1141. [PubMed: 18657041]

Roetzheim RG, Chirikos TN. Breast cancer detection and outcomes in a disability beneficiary population. J Health Care Poor Underserved. 2002; 13(4):461-476. [PubMed: 12407963]

Skinner CSC, Gonin VL, Hanna R, M. Do perceived barriers and benefits vary by mammography stage? Psychology Health \& Medicine. 1997; 2(1):10.

Smeltzer SC, Sharts-Hopko NC, Ott BB, Zimmerman V, Duffin J. Perspectives of women with disabilities on reaching those who are hard to reach. J Neurosci Nurs. 2007; 39(3):163-171. [PubMed: 17591412]

Susan G. Komen for the Cure. Early Detection and Screening: General Recommendations. 2008. Retrieved July 9, 2009, from http://ww5.komen.org/BreastCancer/GeneralRecommendations.html

United States Census Bureau. American Fact Finder. 2011. Retrieved October 31, 2011 from http://factfinder2.census.gov/faces/nav/jsf/pages/index.xhtml

United States Department of Health and Human Services. Healthy People 2020 Topics and Objectives: Disability and Health. 2011. Retrieved October 31, 2011 from http://healthypeople.gov/2020/topicsobjectives2020/objectiveslist.aspx?topicId=9

United States Department of Health and Human Services Office of Disability. Access to Quality Health Services and Disability - A Companion to Chapter 1 of Health People 2010. 2005. Retrieved November 10, 2008, 2008, from http://hhs.gov/od/about/fact_sheets/healthypeople2010.html

United States Department of Justice. 2010 ADA Standards for Accessible Design. Nov 17. 2010 2010Retrieved June 2, 2011, from http://www.ada.gov/reg3a.html\#Anchor-59404

United States Preventive Services Task Force. Screening for breast cancer: U.S. Preventive Services Task Force recommendation statement. Annals of Internal Medicine. 2009; 151(10):716-726. W-236. [PubMed: 19920272]

Yankaskas BC, Dickens P, Bowling JM, Jarman MP, Luken K, Salisbury K, et al. Barriers to Adherence to Screening Mammography Among Women With Disabilities. Am J Public Health. 2009 


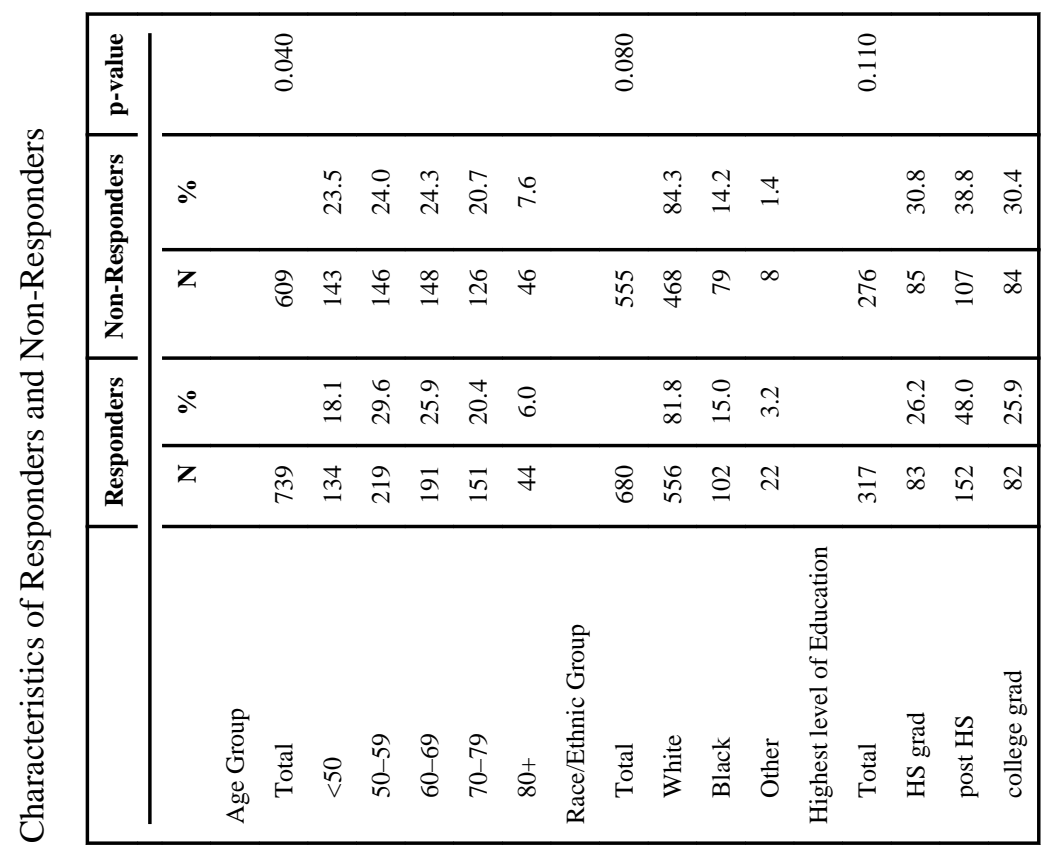

Womens Health Issues. Author manuscript; available in PMC 2013 September 01. 
Table 2

Mammography patient needs $(\mathrm{N}=739)$

\begin{tabular}{|c|c|c|c|}
\hline & Did not need (\%) & Needed, Need Met (\%) & Needed, Not Met (\%) \\
\hline Staff assistance during appointment & 74.4 & 25.2 & 0.4 \\
\hline Staff assistance with paperwork & 81.0 & 19.1 & 0.0 \\
\hline Extra time for appointment & 89.2 & 10.7 & 0.1 \\
\hline Service Animal & 95.6 & 4.3 & 0.1 \\
\hline Handicapped parking space & 69.5 & 24.5 & 3.1 \\
\hline Handrails by entrance & 77.6 & 21.5 & 1.0 \\
\hline Level or ramped entrance & 75.1 & 24.9 & 0.0 \\
\hline Wide doorways & 83.7 & 16.3 & 0.0 \\
\hline Elevator & 80.2 & 19.4 & 0.4 \\
\hline Low reception station, etc. & 86.0 & 13.1 & 1.0 \\
\hline Changing Bench & 43.1 & 56.3 & 0.7 \\
\hline Handrails next to bench & 85.2 & 12.6 & 2.2 \\
\hline Room to turn wheelchair, etc. & 92.8 & 5.5 & 1.6 \\
\hline Private dressing area & 37.0 & 62.0 & 1.1 \\
\hline Wide pathway for wheelchair, etc. & 92.7 & 7.0 & 0.4 \\
\hline Room next to machine to turn.... & 92.9 & 6.5 & 0.7 \\
\hline Sit during mammogram & 88.3 & 9.3 & 2.5 \\
\hline Accessible toilet & 86.7 & 12.8 & 0.4 \\
\hline Accessible sink, etc. & 76.7 & 22.5 & 0.8 \\
\hline Staff assisted guidance & 75.2 & 24.1 & 0.7 \\
\hline Technologist telling what happening... & 39.6 & 60.1 & 0.4 \\
\hline Printed material in other formats & 89.2 & 9.5 & 1.3 \\
\hline Staff to use Relay NC & 94.9 & 4.0 & 1.0 \\
\hline A TTY number at facility & 96.6 & 2.7 & 0.7 \\
\hline An assistive listening device & 95.5 & 4.1 & 0.4 \\
\hline Staff other comm. In waiting room & 92.7 & 6.6 & 0.7 \\
\hline Staff other comm. During mammogram & 93.4 & 6.3 & 0.4 \\
\hline Sign language interpreter & 98.3 & 1.7 & 0.0 \\
\hline
\end{tabular}

Womens Health Issues. Author manuscript; available in PMC 2013 September 01. 


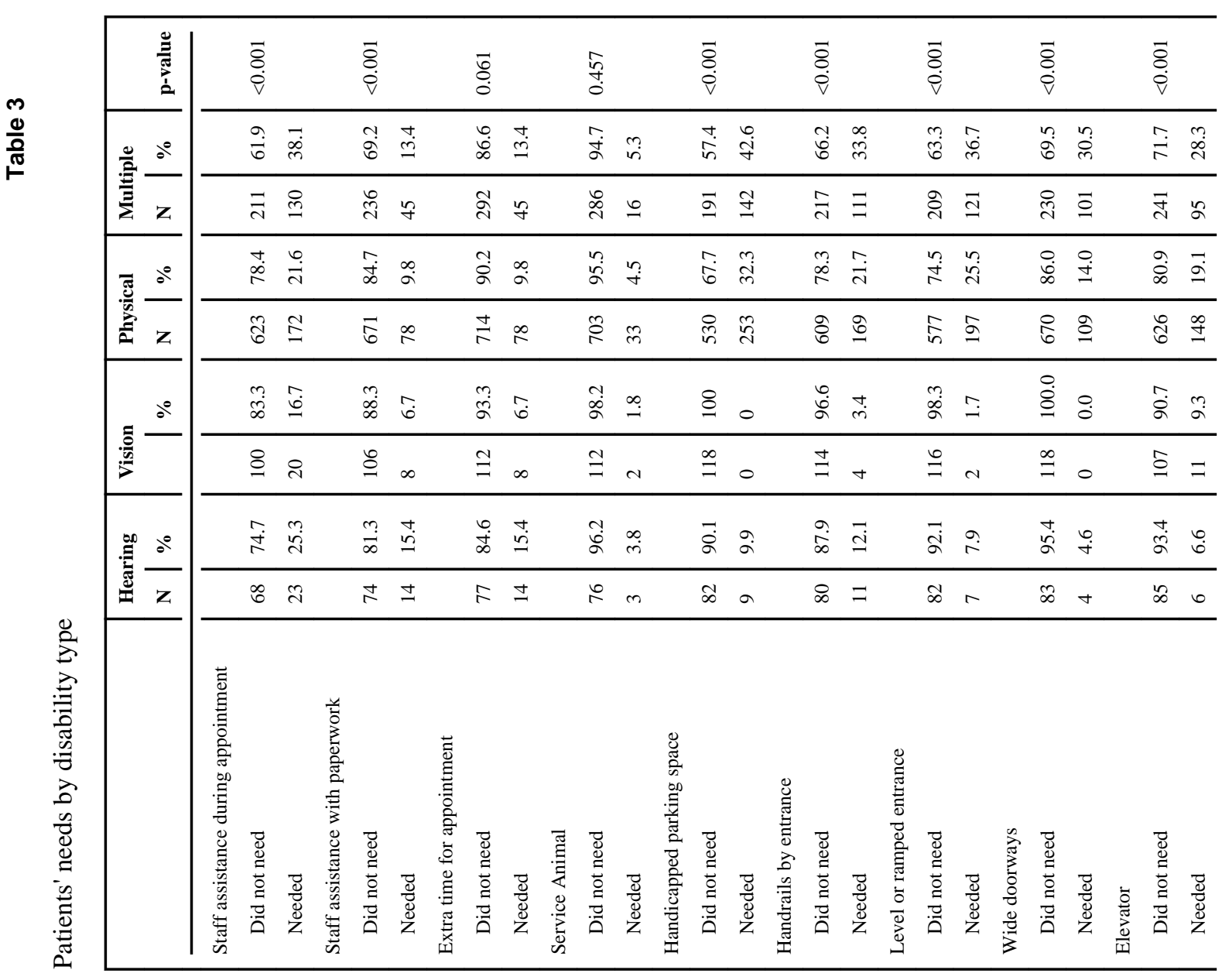

Womens Health Issues. Author manuscript; available in PMC 2013 September 01. 


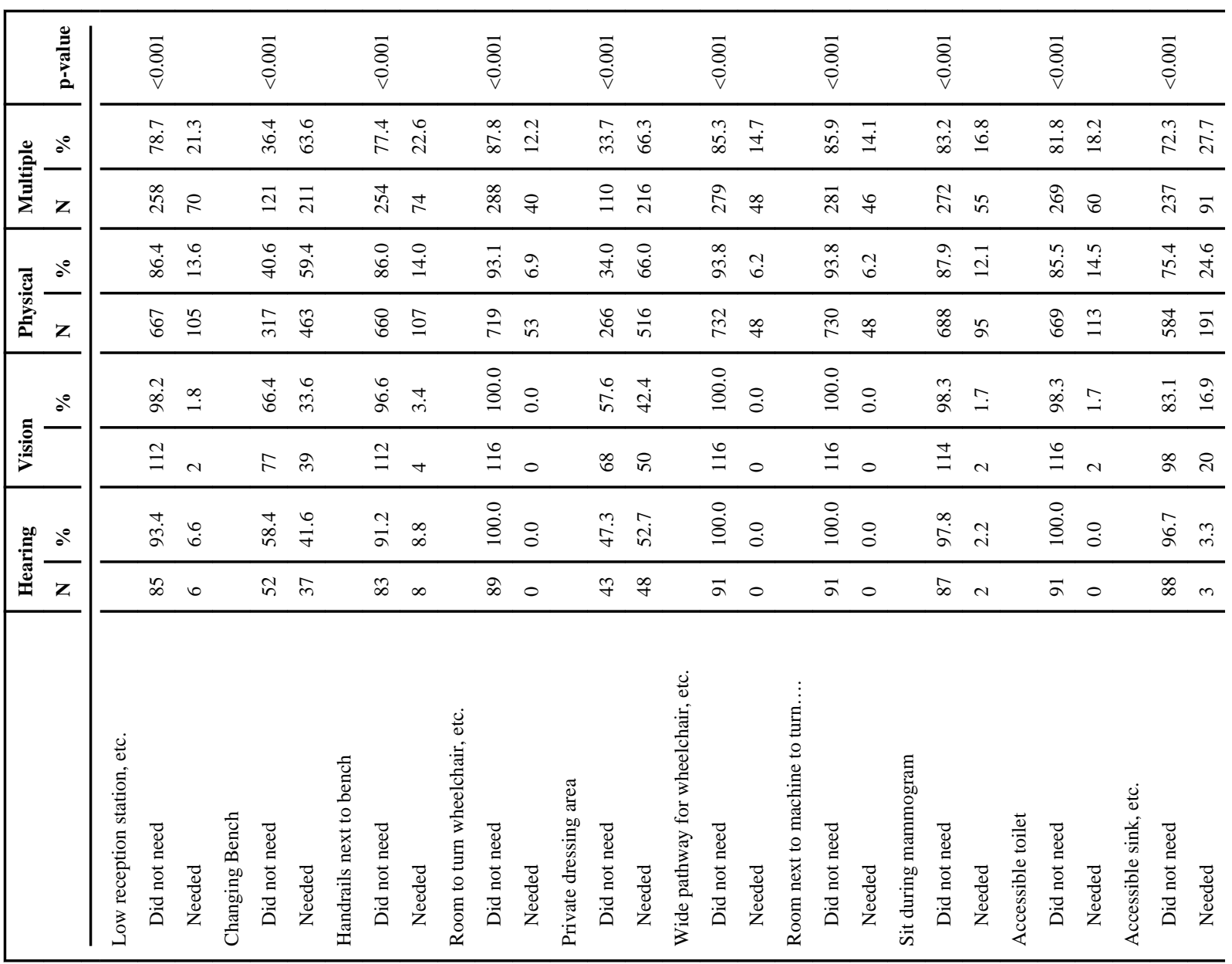

Womens Health Issues. Author manuscript; available in PMC 2013 September 01. 


\begin{tabular}{|c|c|c|c|c|c|c|c|c|c|c|c|c|c|c|c|c|c|c|c|c|c|c|}
\hline 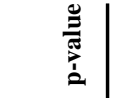 & & $\stackrel{m}{\rightarrow}$ & & $\frac{n}{\frac{n}{n}}$ & & $\begin{array}{l}0 \\
\check{c} \\
0 \\
0\end{array}$ & & & $\stackrel{0}{0}$ & & & $\frac{\text { f }}{0}$ & & & $\begin{array}{l}\text { tut } \\
\text { co } \\
0\end{array}$ & & $\stackrel{\infty}{0}$ & & & $\frac{\text { hे }}{0}$ & & $\frac{n}{n}$ \\
\hline \multirow{2}{*}{$\frac{\infty}{z}$} & & $\vec{g} \stackrel{g}{g}$ & & m. & & & $\dot{0}$ & & & & & s. & $\stackrel{\partial}{\vec{f}}$ & & & & & $\stackrel{\circ}{\stackrel{\mathrm{I}}{ }}$ & & $\stackrel{\sim}{\sigma} \underset{\alpha}{\alpha}$ & & 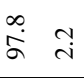 \\
\hline & & $\grave{I}$ ₹ & & 8 & & 䏓 & to & & $\stackrel{n}{=}$ & I & & $\stackrel{\varrho}{\varrho}$ & $a$ & & $\underline{\underline{t}}$ & & $\tilde{\sigma}$ & ส & & $\stackrel{0}{0}$ & & $\stackrel{\infty}{\rightarrow}+$ \\
\hline \multirow{2}{*}{ 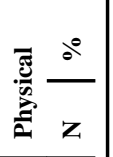 } & & 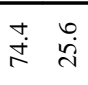 & & ले & & & i & & İ & in & & ఫ̊ँ & $\stackrel{\circ}{\sim}$ & & ñ. & & \& & $\stackrel{\vec{n}}{\mathrm{n}}$ & & $\stackrel{\star \sigma}{\sigma}$ & & 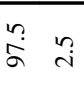 \\
\hline & & $\stackrel{\sim}{\sim} \bar{\infty}$ & & $\Theta$ & & $\stackrel{乛}{خ}$ & $\hat{i}$ & & శె & & & $\underset{\sim}{\infty}$ & $a$ & & $\overline{\widetilde{d}}$ & & ते & 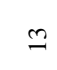 & & 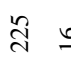 & & तु 0 \\
\hline \multirow{2}{*}{$\frac{50}{2}$} & & $\begin{array}{ll}\stackrel{0}{\infty} \\
\stackrel{i}{i}\end{array}$ & & f & & I & 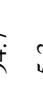 & & $\stackrel{\circ}{8}$ & $\stackrel{\circ}{0}$ & & $\stackrel{8}{\circ}$ & $\stackrel{8}{8}$ & & & & & กู & & $\stackrel{\infty}{\circ}$ & & $\stackrel{\circ}{\stackrel{8}{\circ}}$ \\
\hline & & $\stackrel{\text { ले }}{\circ}$ & & $=$ & & 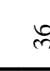 & ? & & 8 & 0 & & 8 & 0 & & 8 & & 5 & + & & $\sigma 0$ & & 80 \\
\hline \multirow{3}{*}{ 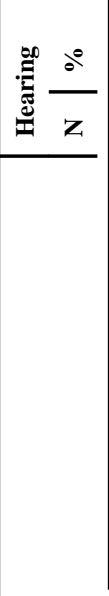 } & & 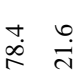 & & $\ddot{8}$ & & & 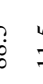 & & $\stackrel{\circ}{\dot{8}}$ & $\stackrel{8}{8}$ & & $\stackrel{\circ}{8}$ & $\stackrel{8}{\circ}$ & & & & & $\stackrel{0}{\circ}$ & & $\stackrel{\circ}{\dot{8}}$ & & $\stackrel{\stackrel{8}{\circ}}{\circ}$ \\
\hline & & $q=$ & & $\hat{\lambda}$ & $\widehat{\vec{v}}$ & fo & 8 & b & $\infty$ & 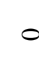 & & $\stackrel{\infty}{\infty}$ & 0 & & in & o & ల & 0 & & $\stackrel{\infty}{\infty}$ & & $\stackrel{m}{m} 0$ \\
\hline & 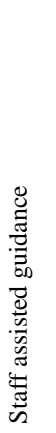 & 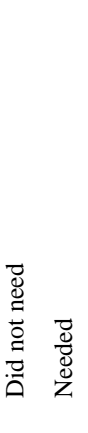 & 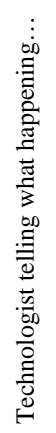 & 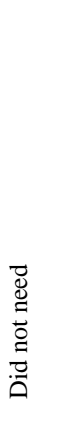 & 芯 & 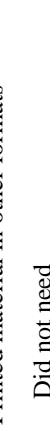 & 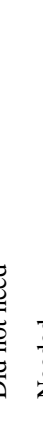 & $\stackrel{5}{5}$ & 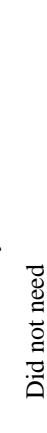 & & $\succsim$ & 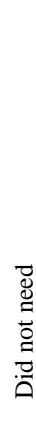 & & 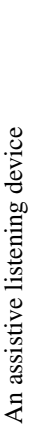 & 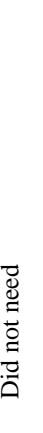 & 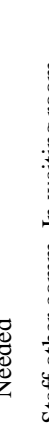 & 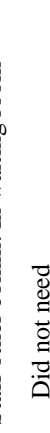 & $\stackrel{\square}{Z}$ & 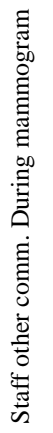 & 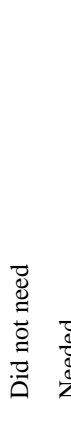 & 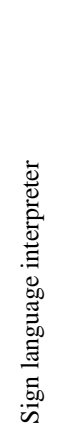 & 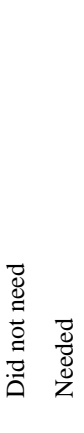 \\
\hline
\end{tabular}




\begin{tabular}{|c|c|c|c|c|c|c|c|c|c|c|c|c|c|c|c|c|c|c|c|c|c|}
\hline 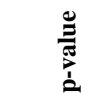 & & \begin{tabular}{l}
0 \\
\multirow{2}{*}{} \\
0 \\
0
\end{tabular} & & 怘 & & $\frac{\pi}{3}$ & & & त్రి & & $\begin{array}{l}\bar{\sigma} \\
\dot{\sigma}\end{array}$ & & $\S$ & 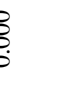 & & $\stackrel{\infty}{a}$ & & & 范 & & $\stackrel{0}{0}$ \\
\hline+80 & & $\stackrel{m}{\stackrel{m}{i}}$ & & $\stackrel{m}{\infty}$ & & $\stackrel{\overbrace{}}{\circ}$ & $\stackrel{\infty}{\circ}$ & & $\stackrel{\circ}{\stackrel{\infty}{\infty}} \stackrel{i}{i}$ & & iे & & & $\hat{\text { हn }}$ & & & $\stackrel{0}{0}$ & & & & 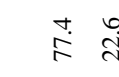 \\
\hline $\mathrm{z}$ & & $\stackrel{\text { c}}{\infty}$ & & $\stackrel{\mathbb{N}}{*}$ & & ్ & $\grave{\lambda}$ & & 의 & & t & & & $\infty$ & & & $\infty$ & & 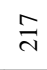 & $n$ & बें \\
\hline$\therefore$ & & 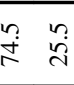 & & $\vec{\infty}$ & & $\underset{\substack{0 \\
\infty}}{r}$ & $\stackrel{m}{=}$ & & 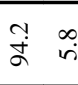 & & $\vec{i}$ & & & $\overrightarrow{0}$ & & & $\overline{7}$ & & $\begin{array}{l}\infty \\
\infty \\
\infty \\
\infty\end{array}$ & $\begin{array}{l}\text { Y } \\
\text { I }\end{array}$ & $\stackrel{\rho}{\infty} \frac{\bar{\infty}}{\infty}$ \\
\hline $\mathrm{z}$ & & f & & $\underset{m}{\stackrel{D}{m}}$ & & $\hat{q}$ & in & & \& & a & $\stackrel{q}{d}=$ & $E$ & 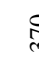 & $2 \infty$ & & $\ddot{\sim}$ & $\stackrel{\infty}{\sigma}$ & & $\stackrel{\infty}{\infty}$ & t & $\underset{\sim}{\infty} \infty$ \\
\hline & 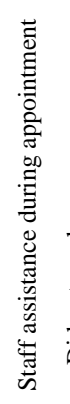 & 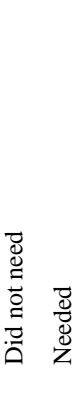 & 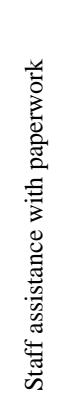 & 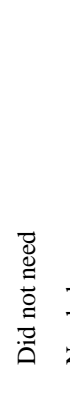 & 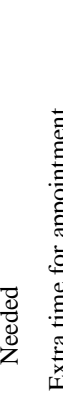 & 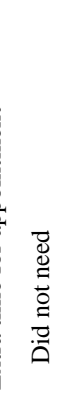 & $\begin{array}{l}\vec{z} \\
\bar{g} \\
\bar{g}\end{array}$ & 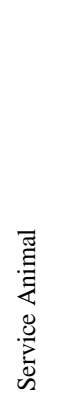 & 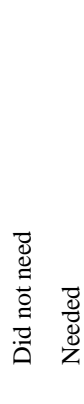 & 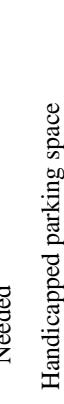 & 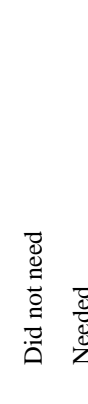 & 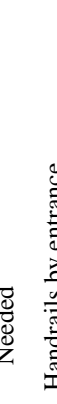 & 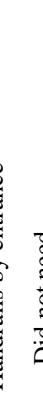 & 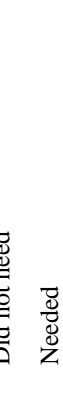 & 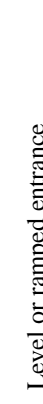 & 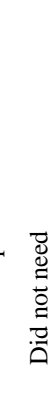 & पू & & 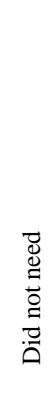 & 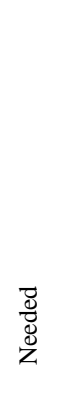 & 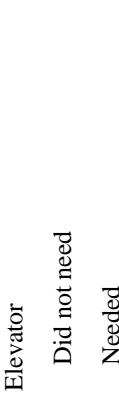 \\
\hline
\end{tabular}

Womens Health Issues. Author manuscript; available in PMC 2013 September 01. 


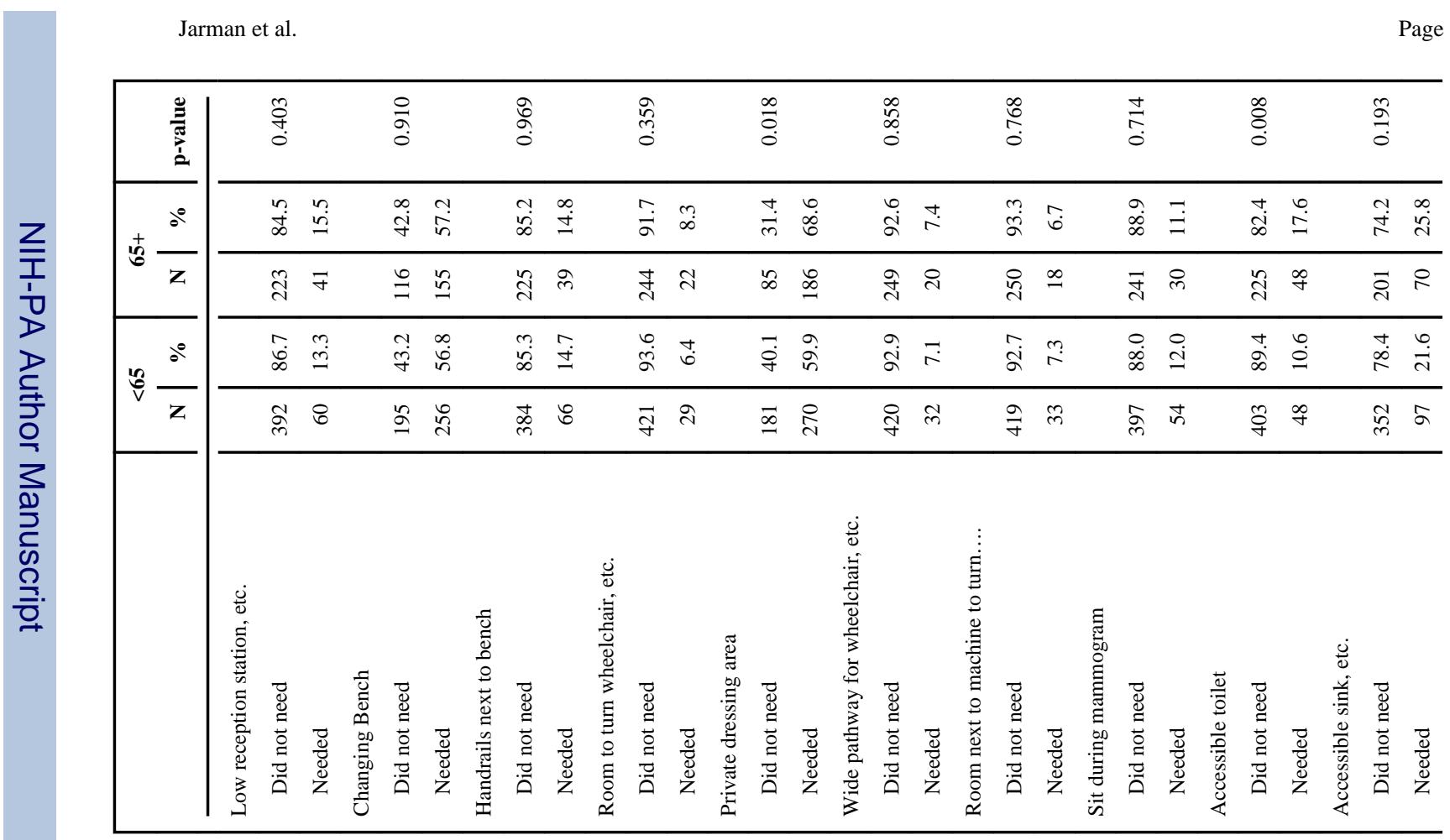

Womens Health Issues. Author manuscript; available in PMC 2013 September 01. 


\begin{tabular}{|c|c|c|c|c|c|c|c|c|c|c|c|c|c|c|c|c|c|c|c|c|c|c|c|}
\hline 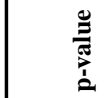 & & ક̊ & & aे & & & 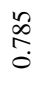 & & & $\begin{array}{l}\text { f } \\
\text { fo }\end{array}$ & & 5 & 8 & & a & & & $\stackrel{+}{\stackrel{t}{0}}$ & & & ๕̊ & & 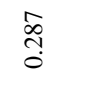 \\
\hline \multirow{2}{*}{$+\frac{5}{z}$} & & 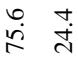 & & & in & & & & & & તુ & & $b_{0}$ & & & $\stackrel{\infty}{+}$ & & & 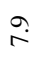 & & ळi & & $\stackrel{c}{\infty} \stackrel{\infty}{0}_{0}^{\infty}$ \\
\hline & & ঃ & & $\bar{n}$ & 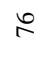 & & $\stackrel{\infty}{\circ}$ & $\simeq$ & & $\bar{I}$ & $\infty$ & & $\vec{I}$ & & & 6 & & $\Xi$ & 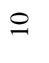 & & $\Xi$ & & $\stackrel{\mathbb{I}}{-}$ \\
\hline \multirow{2}{*}{$\stackrel{\infty}{z} \frac{\infty}{z}$} & & 㸃 & & लें & 8 & & $\ddot{\infty}$ & & & ڤn & $\stackrel{\text { P }}{\rightarrow}$ & & e. & & & $\stackrel{?}{+}$ & & & $\stackrel{\overbrace{}}{6}$ & & $m_{\alpha}^{2}$ & & $\begin{array}{l}\stackrel{0}{*} \\
\stackrel{4}{a}\end{array}$ \\
\hline & & 导 & & A & $\stackrel{m}{=}$ & & 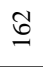 & ิㅗ & & Iิ & $r$ & & $E^{\prime}$ & & 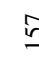 & & & $\cong$ & $=$ & & $\stackrel{\tilde{n}}{2}$ & $E$ & हे \\
\hline & 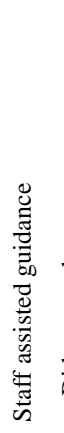 & . & 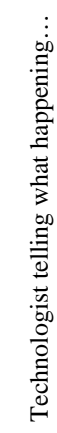 & 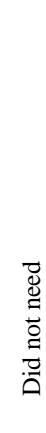 & 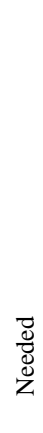 & 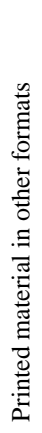 & 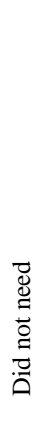 & 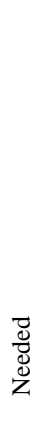 & & 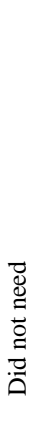 & 荵 & 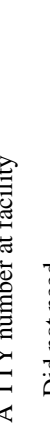 & 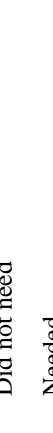 & 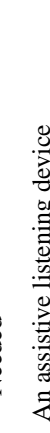 & 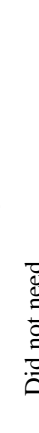 & & 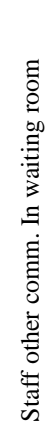 & 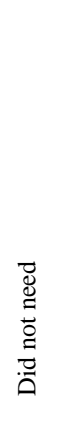 & 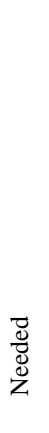 & 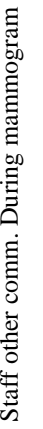 & 总 & . & 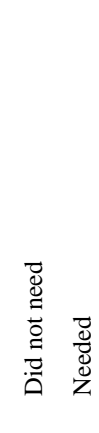 \\
\hline
\end{tabular}


$\frac{10}{0}$

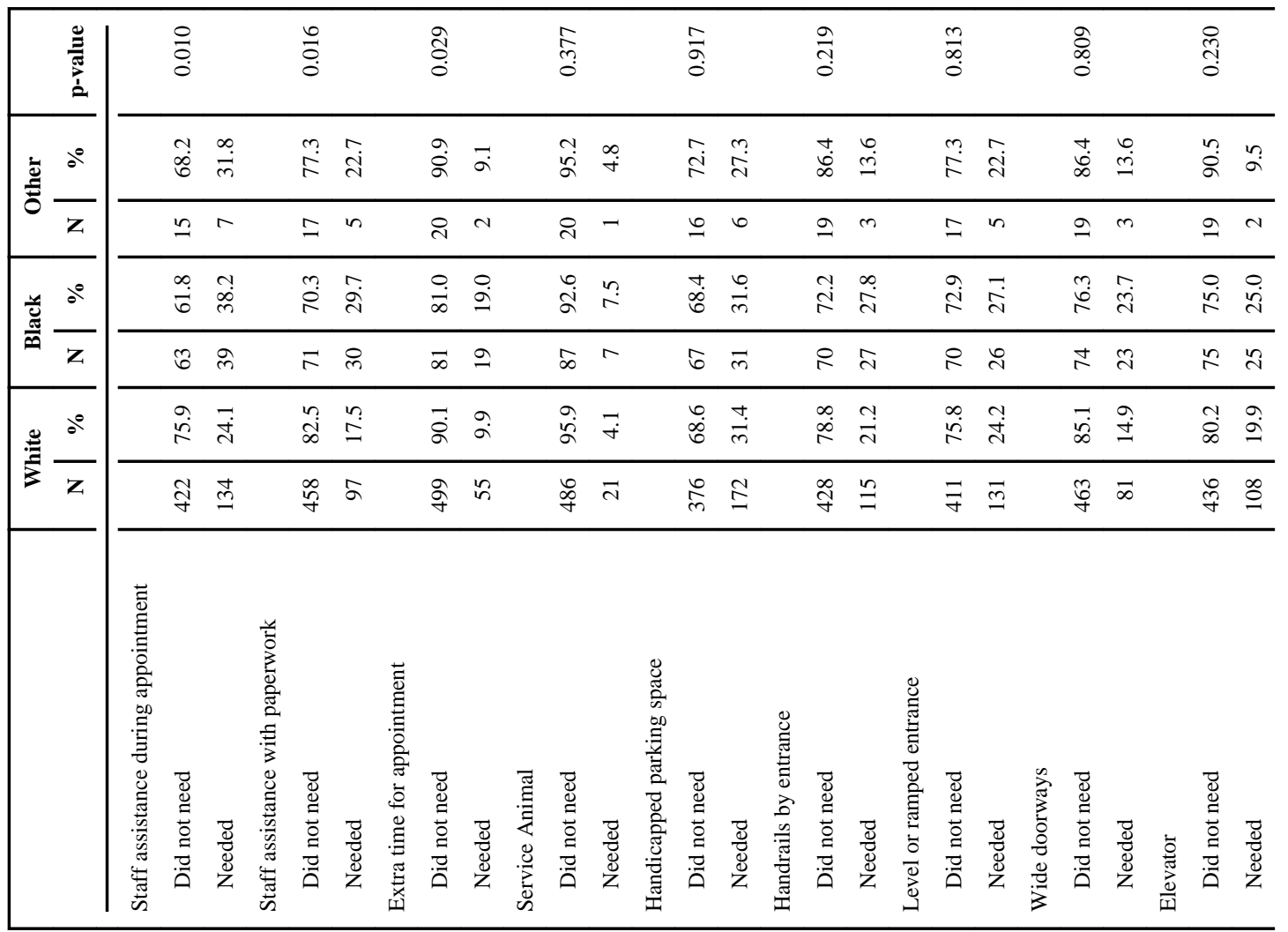

Womens Health Issues. Author manuscript; available in PMC 2013 September 01. 


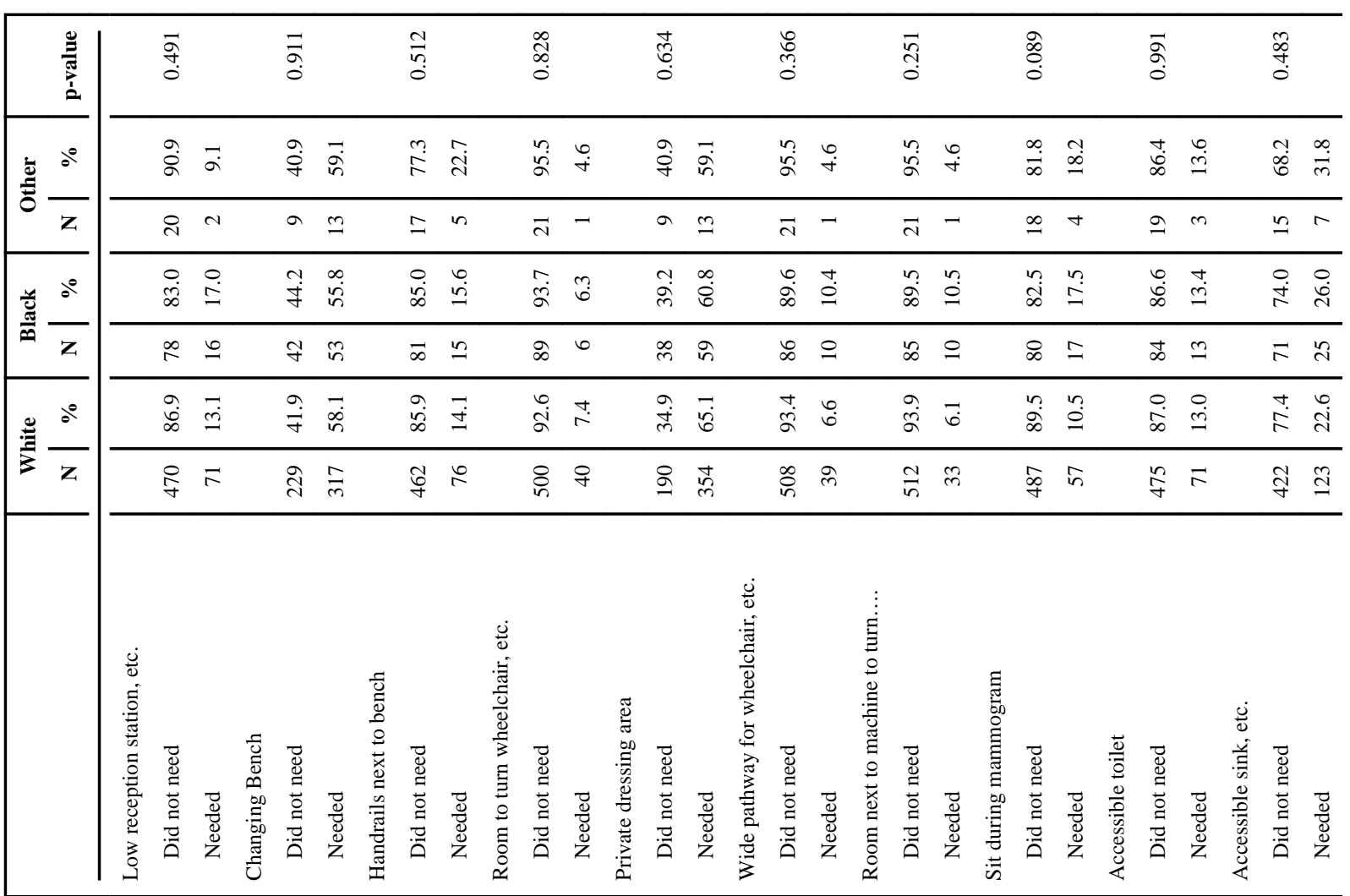




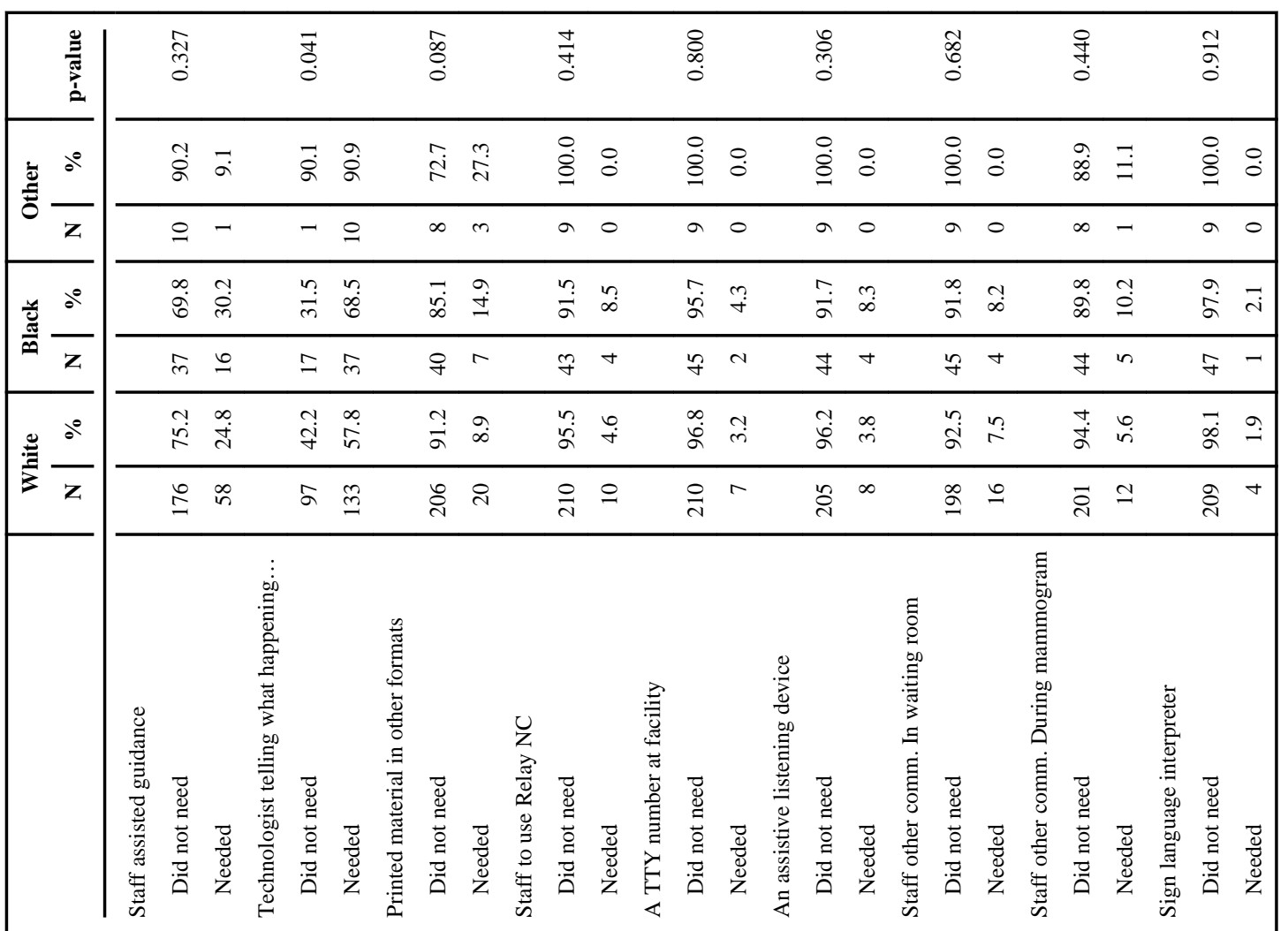

Womens Health Issues. Author manuscript; available in PMC 2013 September 01. 